\title{
A Prospective Observational Study to Find the Incidence of Position Related Injuries in Patients Undergoing Urological Procedures under Anaesthesia
}

\author{
Amruta Vinod Hippalgaonkar1 ${ }^{1}$ Chaitanya Vivek Bokil² \\ ${ }^{1}$ Department of Anaesthesiology, Krishna Institute of Medical Sciences (KIMS), Karad, Maharashtra, India. \\ ${ }^{2}$ Department of General Surgery, Krishna Institute of Medical Sciences (KIMS), Karad, Maharashtra, India.
}

\section{ABSTRACT}

\section{BACKGROUND}

The entire operating team shares the responsibility of patient positioning before a surgical procedure. It is of prime importance to maintain a balance between optimal surgical positioning and the safety of the patient as many of these positions can induce adverse physiological consequences which can affect the haemodynamics of the patient. This study was conducted with the primary objective of determining the incidence of position related injuries and incidents and to analyse the risk factors associated in patients undergoing urological procedures under anaesthesia. The secondary objective was to study the time taken for the injury to resolve and their management.

\section{METHODS}

This is a prospective observational study carried out in adult subjects undergoing urological procedures over a period of 6 months. A thorough preoperative evaluation was carried out which included history taking, examination, preoperative neurological and vascular examination, and pertinent investigations. After the patient was anaesthetized and operative position decided, the nature of position, time taken to position, number of people involved, and the positioning aids used were noted. Any adverse hemodynamic changes occurring during or after the positioning were noted. At the end of the surgery the patient was re-examined for any injuries or incidents related to positioning. Factors contributing to positional injury were categorized and the management of these injuries and the progress was followed up. An analysis sheet was attached. Statistical analysis was done with the help of SPSS Software ver. 10.

\section{RESULTS}

Only one patient sustained nerve injury. The incidence of position related injuries was about $2.1 \%$ with more injuries in patients with general anaesthesia, longer duration of surgery, in those with low BMI. The incidence of position related incidents was seen to be $3.4 \%$ with most common event being hypotension requiring vasopressors and was more prevalent in those undergoing surgery under general anaesthesia.

\section{CONCLUSIONS}

In conclusion, it must be stressed that utmost care must be taken to avoid the occurrence but also to counsel patients undergoing surgeries about the rare possibility of positioning related injuries and incidents under anaesthesia. Every effort should be taken to analyse the underlying precipitating factors and correct them. Symptomatic incidents leading to unstable haemodynamic condition should be treated promptly.

\section{KEY WORDS}

Position Related Injuries, Incidents, Nerve Injury
Corresponding Author: Amruta Vinod Hippalgaonkar, Arogyadarshan, 3, Yadogoapal Peth, Satara-415002, Maharashtra, India. E-mail: h.amrutal@gmail.com

DOI: $10.14260 / \mathrm{jemds} / 2020 / 221$

Financial or Other Competing Interests: None.

How to Cite This Article:

Hippalgaonkar AV, Bokil CV. A prospective observational study to find the incidence of position related injuries in patients undergoing urological procedures under anaesthesia. J. Evolution Med. Dent. Sci. 2020;9(13):1026-1031, $10.14260 / \mathrm{jemds} / 2020 / 221$

Submission 08-01-2020, Peer Review 07-03-2020, Acceptance 13-03-2020, Published 30-03-2020.

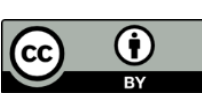




\section{BACKGROUND}

Entire operating team shares the responsibility of proper patient positioning to reach the retroperitoneal and pelvic organs which is a balance between optimal surgical access and safety of patient.(1) In order to access these deep structures various surgical approaches are practiced- open, laparoscopic, endoscopic and robotic. These are done in different positions. The commonly adopted positions involved in urological procedures are:

Supine- This position used for most open urologic procedures. Examples are surgeries of the scrotum, penis, testis, inguinal lymph nodes, open bladder surgeries, ileal conduit, prostatectomy, adrenal glands etc. Some of these procedures are modified with a Trendelenburg position for better visualization of the lower abdominal viscera.

Lithotomy- This position is used for transurethral procedures like ureterostomy, urethroplasty etc. It is also used for open procedures involving the perineum, anus or proximal urethra.

Lateral decubitus position- used for access to the kidneys, collecting systems and adrenal glands. Examples are laparoscopic nephrectomy, open nephrectomy, adrenalectomy etc.

Prone positioning- used for access to the retro peritoneum and upper urinary tracts. Common surgeries performed are percutaneous nephrolithotomy, adrenalectomy, lumbotomy etc.

There are injuries and insults that can occur due to poor patient positioning.(2) The commonly occurring injury appears to be peripheral nerve injury of which ulnar neuropathy is the commonest in one third of all the injuries.(3,4) Surprisingly it has been also observed that ulnar neuropathy can occur without any cause despite careful positioning and proper padding.(5) Many of these positions can affect haemodynamics of the patient resulting in significant cardiovascular and respiratory compromise especially in patients with associated co-morbidities. In a healthy individual to blunt the effects of positional changes complex arterial, venous and cardiac physiological responses come into picture. This maintains perfusion to the vital organs. In an unanaesthetised individual during postural changes the blood pressure is maintained within a narrow range.

General anaesthesia, neuraxial blockade interferes with these auto regulatory mechanisms and renders the patient vulnerable to the changes in haemodynamics. For example neuraxial blockade like spinal anaesthesia causes significant sympathetic block which reduces the preload and blunts the cardiac response to the decreased sympathetic output. Often it is prudent to delay the positioning till patient attains stable haemodynamics. Common undesirable changes include hypotension due to decreased venous return, oxygen desaturation due to ventilation perfusion mismatch. Hence frequent measurement of blood pressure and prompt treatment is vital during positioning. Measures like head down position, prompt administration of IV fluids or vasopressors help during this crucial period. Patient positioning is typically attended to after administration of either regional or general anaesthesia and placement of arterial and venous lines. Hence the protective mechanisms of our body are not in vogue. It is the combined responsibility of both the anaesthesiologist and the surgeon to ensure that the patient is positioned in a physiologically acceptable position without injury and with adequate surgical exposure. Positioning of the patient for urological procedure is thus challenging and requires adequate anaesthetic depth, maintenance of hemodynamic stability, evidence of appropriate oxygenation and preservation of invasive monitoring.

\section{METHODS}

A prospective observational study was carried out over a period of 6 months in patients of either sex undergoing urological procedures under anaesthesia after obtaining written informed consent. A thorough preoperative evaluation included patients' demographic data (age, sex) h/o comorbidities (hypertension, diabetes mellitus, ischaemic heart disease); thorough physical examination with particular stress on preoperative neurological and vascular abnormalities. The type of anaesthesia, perioperative care as also the clinical decisions throughout the perioperative period were at the discretion of the managing anaesthesiologist. The operative position was decided by the urologist and the anaesthetist. The nature of position, time taken to position, number of people involved and the positioning aids (like prone pillows, axillary rolls, armrests/arm boards, saline bags, jelly rests) were noted. Any adverse hemodynamic changes occurring during or after positioning were noted (change in Mean Arterial Pressure/ heart rate $\pm 20 \%$ of baseline in five minutes).

At the end of the surgery the patient was re-examined for any injuries or incidents related to positioning. Any of the following injuries such as chemosis, conjunctival, corneal injury, blindness, peri orbital oedema, extremity motor/sensory deficit, brachial plexus injuries, gangrene and compartment syndrome was looked for. Any critical incidents during positioning such as endotracheal tube dislodgement and kinking, accidental extubation, dislodgement of venous and arterial lines and duration of loss of effective monitoring due to monitor dislodgement were observed. Factors contributing to positional injury were categorized as patient related, procedure related, position related and anaesthesia related. The management of these injuries and their progress were followed up. The incidence and risk factors associated of these injuries and incidents were analysed.

\section{Statistical Analysis}

Data entry was done in Excel. Data analysis was done with the help of SPSS Software version 10. The results were analysed using descriptive statistics and qualitative data was presented with the help of Frequency and Percentage table. Descriptive statistics were done for variables like age, gender, ASA status, BMI, associated co morbidities, position of the patients, type of anaesthesia used. Comparison of proportions were done between those who had position related injuries and incidents and those who did not. 


\section{RESULTS}

Among the 292 patients enrolled in the study, 291 patients were included in the analysis as data was complete. Demographically, $42 \%$ patients were of age between $40-60$ years. There was high male preponderance as $80 \%$ of the urological procedures were done in males. Majority of the patients recruited (55\%) were moderately nourished and had BMI between 18.5 and 29.9. It was also observed that half of the patients were ASA 1 patients (51\%). Half (50\%) of the population recruited into the study had associated co morbidities, hypertension being the highest (51\%) followed by diabetes mellitus (42\%). Only 2 patients had pre-operative neurological deficit. One had post-polio residual paralysis of the left leg and other had right vocal cord paralysis.

Regional anaesthetic procedures had a little higher incidence (47\%) compared to general anaesthesia (43\%) with lithotomy position being used for $55 \%$ of the patients recruited. In $58 \%$ of patients both the upper limbs were kept in adducted position whereas in about $36 \%$ abducted position of upper limbs was kept. Major chunk of the patients underwent endoscopic urological procedures (53\%). In $39 \%$ of the urological procedures done, four personnel were available for positioning of the patient and time taken to position the patients was less than or equal to five minutes in majority of the patients (87\%). Positioning aids were used in most of the procedures (70\%), most commonly used was the leg stirrups (61\%) followed by brachial plexus gelly rolls and the saline bags (44\%). Warming devices were used in $80 \%$ of the procedures of which the most common one was the Bair Hugger.

In a major percentage (98\%) of cases done under general anaesthesia, the endotracheal tube/ laryngeal mask airway was fixed with the help of the Elastoplast as Durapore and Tegaderm was not considered safe enough by most of the anaesthesiologists. Majority of the surgeries (68\%) lasted between 1-4 hours. The intermittent boluses of vasopressors either ephedrine or phenylephrine were used in $16 \%$ of the patients who had short periods of hypotension and most of the patients had between 2 and 3 boluses (59.6\%). It was observed that as an infusion for treatment of hypotension only noradrenaline was used in 5 patients $(1.74 \%)$. Intraoperative hypotension was observed only in 12 patients in whom 7 of them had a significant drop of blood pressure of MAP less than $60 \mathrm{mmHg}$ that lasted for more than 15 minutes of hypotension.

Six injuries were noted with an incidence of $2.1 \%$. Four patients had eye injuries; 2 cases of chemosis and 2 of redness in the eyes and 4 incidences of periorbital oedema. Some of the patients had a combination of injuries in the eye. Two patients had injuries in the head and neck region both of which were lip oedema in the prone position. Two patients had lower limb injuries; one had skin oedema of the leg while other had sensory neuropathy on the left leg. There were no vascular injuries, chest and abdominal area injuries or injuries to the brachial plexus. The incidence of position related incidents was reported to be $3.4 \%$. In 5 patients, hemodynamic changes were seen, of which 4 had hypotension and 1 had bradycardia. Four incidents were seen related to the airway, from which in 2 patients there was endotracheal tube dislodgement, one patient had endotracheal tube kink and one patient sustained accidental extubation. One more incident was reported in a patient who sustained cautery burns in the sacral area. Half the injuries occurred in the prone position ( 3 out of 6 ), the other two in the lithotomy position and only one injury in supine position.

Four events occurred in lateral position whereas three in prone position. As expected prone and lateral positions were associated with higher incidents and position related injuries. Only two events were noticed in the lithotomy position and one in supine position. It is significant to note that only 2 incidents occurred although lithotomy position was used in majority of cases (158 times). Four injuries were noted of 126 patients who underwent general anaesthesia, while only one injury each was noted among 137 patients who received spinal anaesthesia and 27 patients with combined general and regional anaesthesia. Out of the 10 incidents reported, 9 were seen under general anaesthesia and only one under combined anaesthesia. No adverse events were seen in spinal anaesthesia. Out of 201 surgeries in duration between 1-4 hours three injuries occurred and all in prone position. The other three occurred in duration for $>4$ hours (only 20 surgeries in this category) which is quite significant (2 in lithotomy and one in supine). No injuries were reported in surgeries performed in less than 1 hour (51 in lithotomy and 19 in supine).

\begin{tabular}{|cc|}
\hline Position Injuries & Number (\%) \\
No & $285(97.9)$ \\
Yes & $6(2.1)$ \\
Position-Related Incidents & Number $(\%)$ \\
No & $281(96.6)$ \\
Yes & $10(3.4)$ \\
\hline Table 1. Position Related Injuries and Incidents \\
\hline
\end{tabular}

\begin{tabular}{|c|c|c|c|c|c|c|c|c|c|}
\hline \multirow[t]{2}{*}{$\begin{array}{c}\text { Position of } \\
\text { the } \\
\text { Patient for } \\
\text { Surgery }\end{array}$} & \multicolumn{2}{|c|}{$\begin{array}{l}\quad<1 \mathrm{hr} . \\
\text { Position } \\
\text { Related } \\
\text { Injuries }\end{array}$} & \multirow[t]{2}{*}{ Total } & \multicolumn{2}{|c|}{\begin{tabular}{l}
\multicolumn{1}{c}{ 1- 4 hr } \\
Position \\
Related \\
Injuries
\end{tabular}} & \multirow[t]{2}{*}{ Total } & \multicolumn{2}{|c|}{$\begin{array}{l}\quad>4 \mathrm{~h} \text {. } \\
\text { Position } \\
\text { Related } \\
\text { Injuries }\end{array}$} & \multirow[t]{2}{*}{ Total } \\
\hline & No & Yes & & No & Yes & & No & Yes & \\
\hline Supine & 19 & 0 & 19 & 22 & 0 & 22 & 9 & 1 & 10 \\
\hline Prone & 0 & 0 & 0 & 24 & 3 & 27 & 0 & 0 & 0 \\
\hline Lateral & 0 & 0 & 0 & 38 & 0 & 38 & 2 & 0 & 2 \\
\hline $\begin{array}{c}\text { Lateral } \\
\text { decubitus }\end{array}$ & 0 & 0 & 0 & 8 & 0 & 8 & 1 & 0 & 1 \\
\hline Lithotomy & 51 & 0 & 51 & 102 & 0 & 102 & 4 & 2 & 6 \\
\hline High lithotomy & 0 & 0 & 0 & 2 & 0 & 2 & 1 & 0 & 1 \\
\hline $\begin{array}{c}\text { Reverse } \\
\text { Trendelenburg }\end{array}$ & 0 & 0 & 0 & 1 & 0 & 1 & 0 & 0 & 0 \\
\hline Head down tilt & 0 & 0 & 0 & 1 & 0 & 1 & 0 & 0 & 0 \\
\hline Total & 70 & $\mathbf{0}$ & 70 & 198 & 3 & 201 & 17 & 3 & 20 \\
\hline$T a b$ & Com & $\begin{array}{l}\text { iso } \\
\text { jju }\end{array}$ & $f D u$ & ion & se & $\begin{array}{l}\text { ery } \\
\text { he P }\end{array}$ & $\begin{array}{l}\text { ith } P \\
\text { tient }\end{array}$ & itic & \\
\hline
\end{tabular}

\begin{tabular}{|c|c|c|c|c|c|c|c|c|c|}
\hline \multirow[t]{2}{*}{$\begin{array}{l}\text { Position of } \\
\text { the Patient } \\
\text { for Surgery }\end{array}$} & \multicolumn{2}{|c|}{$\begin{array}{l}\qquad<1 \mathrm{hr} \\
\text { Position } \\
\text { Related } \\
\text { Incidents }\end{array}$} & \multirow[t]{2}{*}{ Total } & \multicolumn{2}{|c|}{$\begin{array}{l}\text { 1-4 hr } \\
\text { Position } \\
\text { Related } \\
\text { Incidents }\end{array}$} & \multirow[t]{2}{*}{ Total } & \multicolumn{2}{|c|}{$\begin{array}{l}>4 \mathrm{hrs} . \\
\text { Position } \\
\text { Related } \\
\text { Incidents }\end{array}$} & \multirow[t]{2}{*}{ Total } \\
\hline & No & Yes & & No & Yes & & No & Yes & \\
\hline Supine & 19 & 0 & 19 & 21 & 1 & 22 & 10 & 0 & 10 \\
\hline Prone & 0 & 0 & 0 & 24 & 3 & 27 & 0 & 0 & 0 \\
\hline Lateral & 0 & 0 & 0 & 34 & 4 & 38 & 2 & 0 & 2 \\
\hline $\begin{array}{c}\text { Lateral } \\
\text { decubitus }\end{array}$ & 0 & 0 & 0 & 8 & 0 & 8 & 1 & 0 & 1 \\
\hline Lithotomy & 50 & 1 & 51 & 101 & 1 & 102 & 5 & 0 & 5 \\
\hline High lithotomy & 0 & 0 & 0 & 2 & 0 & 2 & 1 & 0 & 1 \\
\hline $\begin{array}{c}\text { Reverse } \\
\text { Trendelenburg }\end{array}$ & 0 & 0 & 0 & 1 & 0 & 1 & 0 & 0 & 0 \\
\hline Head down tilt & 0 & 0 & 0 & 1 & 0 & 1 & 0 & 0 & 0 \\
\hline Total & 69 & 1 & 70 & 192 & 9 & 201 & 19 & $\mathbf{0}$ & 19 \\
\hline
\end{tabular}

9 incidents were reported in the surgeries between 1-4 hours ( 4 events in lateral position, three in prone and one in lithotomy). One event was seen in lithotomy position but 
surgery lasted for $<1$ hour. No adverse events were reported in procedures lasting for $>4$ hours. Out of the procedures lasting between 1-4 hours three injuries were noted under general anaesthesia (102), with no injuries in spinal and combined anaesthesia. Out of only 20 surgeries for $>4$ hours three injuries were noted, shared equally in GA, spinal and combined which is quite significant. Of the 70 procedures of $<$ 1 hour, majority (55) were done under spinal but none of the patients suffered injuries in any position. Most of the position related incidents occurred in surgeries of 1-4 hours duration (8 under general anaesthesia and one during combined anaesthesia). The remaining one incident was seen in a surgery $<1$ hour and under general anaesthesia. Of the 19 procedures which lasted for $>4$ hours, there were no incidents noted.

Three injuries were seen in normally built individuals (160) in the study population (1.8\%). Two occurred in underweight individuals which may be of significance $(6 \%)$. Only one occurred in the overweight and none in the obese individuals. Of 10 incidents that occurred, 4 each were noted in normal built (160) and overweight (85). Two events occurred in underweight. Interestingly the obese category did not suffer any adverse events.

\begin{tabular}{|c|c|c|c|c|c|c|c|c|c|}
\hline \multirow[t]{2}{*}{$\begin{array}{c}\text { Type of } \\
\text { Anaesthesia } \\
\text { Used }\end{array}$} & \multicolumn{2}{|c|}{$\begin{array}{l}\quad<1 \mathrm{hr} . \\
\text { Position } \\
\text { Related } \\
\text { Injury }\end{array}$} & \multirow[t]{2}{*}{ Total } & \multicolumn{2}{|c|}{$\begin{array}{l}\text { 1- } 4 \mathrm{hr} \\
\text { Position } \\
\text { Related } \\
\text { Injury }\end{array}$} & \multirow[t]{2}{*}{$\begin{array}{l}\text { S. } \\
\text { Total }\end{array}$} & \multicolumn{2}{|c|}{$\begin{array}{l}\quad>4 \mathrm{hrs} \\
\text { Position } \\
\text { Related } \\
\text { Injury }\end{array}$} & \multirow[t]{2}{*}{ Total } \\
\hline & No & Yes & & No & Yes & & No & Yes & \\
\hline GA & 14 & 0 & 14 & 99 & 3 & 102 & 9 & 1 & 10 \\
\hline Spi & 55 & 0 & 55 & 80 & 0 & 80 & 1 & 1 & 2 \\
\hline Combined & 0 & 0 & 0 & 19 & 0 & 19 & 7 & 1 & 8 \\
\hline Local & 1 & 0 & 1 & 0 & 0 & 0 & 0 & 0 & 0 \\
\hline Total & 70 & 0 & 70 & 198 & 3 & 201 & 17 & 3 & 20 \\
\hline
\end{tabular}

\begin{tabular}{|c|c|c|c|c|c|c|c|c|c|}
\hline \multirow[t]{2}{*}{$\begin{array}{c}\text { Type of } \\
\text { Anaesthesia } \\
\text { Used }\end{array}$} & \multicolumn{2}{|c|}{$\begin{array}{l}\quad<1 \mathrm{hr} \\
\text { Position } \\
\text { Related } \\
\text { Incidents }\end{array}$} & \multirow[t]{2}{*}{ Total } & \multicolumn{2}{|c|}{$\begin{array}{l}\text { 1-4 hrs. } \\
\text { Position } \\
\text { Related } \\
\text { Incidents }\end{array}$} & \multirow[t]{2}{*}{ Total } & \multicolumn{2}{|c|}{$\begin{array}{l}\quad>4 \mathrm{hr} \\
\text { Position } \\
\text { Related } \\
\text { Incidents }\end{array}$} & \multirow[t]{2}{*}{ Total } \\
\hline & No & Yes & & No & Yes & & No & Yes & \\
\hline GA & 13 & 1 & 14 & 94 & 8 & 102 & 10 & 0 & 10 \\
\hline Spinal & 55 & 0 & 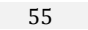 & 80 & 0 & 80 & 2 & 0 & 2 \\
\hline Combined & 0 & 0 & 0 & 18 & 1 & 19 & 7 & 0 & 7 \\
\hline Local & 1 & 0 & 1 & 0 & 0 & 0 & 0 & 0 & 0 \\
\hline Total & 69 & 1 & 70 & 192 & 9 & 201 & 19 & 0 & 19 \\
\hline
\end{tabular}

\section{DISCUSSION}

Though best surgical access depends on optimal positioning, care must be taken to minimize the risk of injury and adverse outcomes that can occur. Urological procedures involve different positions for access to the urogenital organs, pelvis, kidneys and the retro peritoneum. Each position carries some risk which is more especially in the anaesthetized patients. Position related injury can be due to tissue compression, stretch, blunt or sharp trauma, air embolism, organ under perfusion, ischaemia. $(4,6)$ Positioning related nerve injuries are usually preventable and were first documented in the 1800s. (7) It is important to distinguish the nerve injury (due to positioning) from other injuries occurring due to neurological disorders, cervical spinal injuries and other autoimmune neurological disorders. ${ }^{(8)}$
A retrospective study by Welch $\mathrm{MB}$ et al for a 10 year period showed that injuries due to urological procedures constituted $15 \%$ of all the cases reported and $13 \%$ of all the peripheral nerve injuries that were reported.(9) Ten nerve injuries (7\%) were directly related to patient positioning according to American society of anaesthesiologists closed claims project, since 1990, in 143 claims reviewed. In a study done by Parks et al, the incidence of nerve injury in open

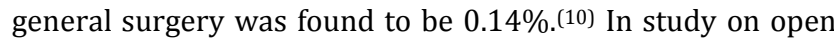
retropubic radical prostatectomy,(11) the incidence was seen $0.3 \%$. In our study only one patient sustained nerve injury, an isolated case of sensory neuropathy in the lateral part of the left leg. The incidence calculated is $0.3 \%$ similar to the study done on open retropubic radical prostatectomy. In patients undergoing robotic assisted urological surgery the incidence of positioning injuries reported was $6.6 \%$ by James T Mills et al.(12) Wolf et al calculated an incidence of $2.7 \%$ neuromuscular injuries, in patients who underwent laparoscopic urological procedures.(13) Our study did not report any neuromuscular injury to patients in laparoscopic procedure, but the incidence for position related injuries in all the urological procedures is about $2.1 \%$ which is slightly less than the above study probably due to the smaller sample size. Injuries reported were redness of eyes, chemosis, periorbital oedema, lip oedema, lower limb oedema and sensory neuropraxia.

Care must be taken to minimize the excessive rotation of head, excessive increase in intraabdominal pressure.(14,15) Abduction of the arm above 90 degree in situations where the hand rests above the head also lead to stretch on the roots of the plexus especially in prone position. $(16,17)$ The use of steep Trendelenburg in urological procedures with the help of shoulder braces can cause severe stretch and compression of the brachial plexus.(18) Arms should be placed on strong arm rests that prevent dorsal hyperextension.(4) Ideally the arms should be extended neutrally or slightly supinated.(19,20) One has to make sure that the blood pressure cuffs are properly placed and not distal so that it does not press on the ulnar nerve while inflating.(21) Mechanism of injury in lithotomy position is the hip flexion with knee extension that stretches both the common peroneal nerve and the sciatic nerve.(22) The commonest position in urological procedures where compartment syndrome is seen is lithotomy position where affected limb can undergo severe ischemic damage with disability and risk of death if emergency decompression surgery is not undertaken. $(23,24,25,26,27)$ ICP (intra-compartment pressure) increases have also been noticed in the lateral decubitus and the full renal- break positions.(28) PION (posterior ischemic optic neuropathy) is a complication in the Trendelenburg position. The possible mechanism is due to ischemic insult to optic nerve.(29,30) This is due to multiple factors like hypoxia, increased blood loss, prolonged hypotension, fluid overload, increased venous pressure and presence of other comorbidities. (31,32) Risk factors identified for the injuries are tobacco use, slim built, prolonged surgery lasting for more than three hours.(33) In a study conducted on 185 patients for urethral reconstruction done in the high lithotomy position, it was noticed that $18(10 \%)$ position related injuries were seen of which four of them were severe.(34) Another study reported that male sex, body mass index greater than $25 \mathrm{Kg} / \mathrm{m}^{2}$, use of fully flexed position, gel padding increased the skin to surface interface pressures.(35) Turning prone should be done with utmost care as rotation of 
the head can cause ischemia to the carotid and vertebral arteries which can progress to a cerebrovascular accident and breasts should be kept medially to avoid compression laterally.(36) Trendelenburg position may result in migration of the endotracheal tube to the right main stem bronchus resulting in hypoventilation of the left lung.(37) When spinal anaesthesia is performed in lateral position with hyperbaric bupivacaine it causes greater cephalad spread and a delayed onset of hypotension.(38) Likewise the lateral position is also seen to be beneficial especially in patients with unilateral lung infiltrates. This is done by positioning the affected lung in the non-dependent position resulting in improved oxygenation.(39)

In our study the incidence of position related incidents was $3.4 \%$ which included hypotension, bradycardia, endotracheal/ LMA tube dislodgement, tube kink, accidental extubation and cautery burns, most frequent being hypotension. Airway incidents were also significant. An incident that could have been potentially serious was a cautery burn in the sacral area though the cautery plate was placed on the left leg. This was noticed on second post-op day but fortunately healed with no significant morbidity. The other events like hemodynamic changes, tube kink, dislodgement and accidental extubation did not pose much serious problems and were managed well.

\section{Limitations}

We could recruit only 291 patients due to time constraints and the incidence of injuries and incidents are very few to show any statistically significant values.

\section{CONCLUSIONS}

In accordance with the aim of our study, in urological procedures under anaesthesia we observed the incidence of injuries related to position to be $2.1 \%$ which is less than previous studies and that of incidents related to positioning to be $3.4 \%$.

In conclusion, it must be stressed that positioning related injuries and incidents under anaesthesia can go unrecognized and utmost care must be taken to avoid the occurrence of these injuries and incidents. These are more common in patients undergoing long procedures under general anaesthesia and those undergoing PCNL in the prone position. Hence it is important to counsel patients undergoing surgeries about the rare possibility of positioning injuries and incidents especially in long surgeries. Although the incidence of position related injury is less compared to the Western population, continuing the study to achieve a larger sample size would throw more light on the incidence of position related injury and incidents, especially in the Indian subcontinent.

\section{REFERENCES}

[1] Knight DJW, Mahajan RP. Patient positioning in anaesthesia. Contin Educ Anaesth Crit Care Pain 2004;4 (5):160-3.

[2] Cheney FW, Domino KB, Caplan RA, et al. Nerve injury associated with anesthesia: a closed claims analysis. Anesthesiology 1990;90 (4):1062-9.
[3] Kroll DA, Caplan RA, Posner K, et al. Nerve injury associated with anesthesia. Anesthesiology 1990;73 (2):202-7.

[4] Schubert A. Positioning injuries in anesthesia: an update. Adv Anesth 2008;26:31-65.

[5] Stoelting RK. Postoperative ulnar nerve palsy--is it a preventable complication? Anesth Analg 1993;76 (1):7-9.

[6] Dawson DM, Krarup C. Perioperative nerve lesions. Arch Neurol 1989;46 (12):1355-60.

[7] Winfree CJ, Kline DG. Intraoperative positioning nerve injuries. Surg Neurol 2005;63 (1):5-18.

[8] Arnason BG, Asbury AK. Idiopathic polyneuritis after surgery. Arch Neurol 1968;18 (5):500-7.

[9] Welch MB, Brummett CM, Welch TD, et al. Perioperative peripheral nerve injuries: a retrospective study of 380,680 cases during a 10-year period at a single institution. Anesthesiology 2009;111 (3):490-7.

[10] Parks BJ. Postoperative peripheral neuropathies. Surgery 1973;74 (3):348-57.

[11] Catalona WJ, Carvalhal GF, Mager DE, et al. Potency, continence and complication rates in 1,870 consecutive radical retropubic prostatectomies. J Urol 1999;162 (2):433-8.

[12] Mills JT, Burris MB, Warburton DJ, et al. Positioning injuries associated with robotic assisted urological surgery. J Urol 2013;190 (2):580-4.

[13] Wolf JS, Marcovich R, Gill IS, et al. Survey of neuromuscular injuries to the patient and surgeon during urologic laparoscopic surgery. Urology 2000;55 (6):8316.

[14] Toole JF. Effects of change of head, limb and body position on cephalic circulation. N Engl J Med 1968;279 (6):30711.

[15] DiStefano VJ, Klein KS, Nixon JE, et al. Intra-operative analysis of the effects of position and body habitus on surgery of the low back. A preliminary report. Clin Orthop Relat Res 1974; (99):51-6.

[16] Britt BA, Gordon RA. Peripheral nerve injuries associated with anaesthesia. Can Anaesth Soc J 1964;11:514-36.

[17] Anderton JM, Schady W, Markham DE. An unusual cause of postoperative brachial plexus palsy. Br J Anaesth 1994;72 (5):605-7.

[18] Jackson L, Keats AS. Mechanism of brachial plexus palsy following anesthesia. Anesthesiology 1965;26:190-4.

[19] American Society of Anesthesiologists Task Force on Prevention of Perioperative Peripheral Neuropathies. Practice advisory for the prevention of perioperative peripheral neuropathies: an updated report by the American Society of Anesthesiologists Task Force on prevention of perioperative peripheral neuropathies. Anesthesiology 2011;114 (4):741-54.

[20] Tuncali BE, Tuncali B, Kuvaki B, et al. Radial nerve injury after general anaesthesia in the lateral decubitus position. Anaesthesia 2005;60 (6):602-4.

[21] Sy WP. Ulnar nerve palsy possibly related to use of automatically cycled blood pressure cuff. Anesth Analg 1981;60 (9):687-8.

[22] Burkhart FL, Daly JW. Sciatic and peroneal nerve injury: a complication of vaginal operations. Obstet Gynecol 1966;28 (1):99-102. 
[23] Ubee SS, Manikandan R, Athmanathan N, et al. Compartment syndrome in urological practice. BJU Int 2009;104 (5):577-8.

[24] Heppenstall B, Tan V. Well-leg compartment syndrome. Lancet 1999;354 (9183):970.

[25] Leff RG, Shapiro SR. Lower extremity complications of the lithotomy position: prevention and management. J Urol 1979;122 (1):138-9.

[26] Simms MS, Terry TR. Well leg compartment syndrome after pelvic and perineal surgery in the lithotomy position. Postgrad Med J 2005;81 (958):534-6.

[27] Akhavan A, Gainsburg DM, Stock JA. Complications associated with patient positioning in urologic surgery. Urology 2010;76 (6):1309-16.

[28] Owen CA, Mubarak SJ, Hargens AR, et al. Intramuscular pressures with limb compression. Clarification of the pathogenesis of the drug-induced muscle-compartment syndrome. N Engl J Med 1979;300 (21):1169-72.

[29] Phong SVN, Koh LKD. Anaesthesia for robotic-assisted radical prostatectomy: considerations for laparoscopy in the Trendelenburg position. Anaesth Intensive Care 2007;35 (2):281-5.

[30] Weber ED, Colyer MH, Lesser RL, et al. Posterior ischemic optic neuropathy after minimally invasive prostatectomy. J Neuroophthalmol 2007;27 (4):285-7.

[31] Foroozan R. Shock-induced anterior ischaemic optic neuropathy after radical prostatectomy. Clin Experiment Ophthalmol 2004;32(4):438-9.
[32] Williams GC, Lee AG, Adler HL, et al. Bilateral anterior ischemic optic neuropathy and branch retinal artery occlusion after radical prostatectomy. J Urol 1999;162(4):1384-5.

[33] Warner MA, Warner DO, Harper CM, et al. Lower extremity neuropathies associated with lithotomy positions. Anesthesiology 2000;93(4):938-42.

[34] Anema JG, Morey AF, McAninch JW, et al. Complications related to the high lithotomy position during urethral reconstruction. J Urol 2000;164(2):360-3.

[35] Deane LA, Lee HJ, Box GN, et al. Third place: Flank position is associated with higher skin-to-surface interface pressures in men versus women: implications for laparoscopic renal surgery and the risk of rhabdomyolysis. J Endourol Soc 2008;22(6):1147-51.

[36] Edgcombe H, Carter K, Yarrow S. Anaesthesia in the prone position. Br J Anaesth 2008;100(2):165-83.

[37] Heinonen J, Takki S, Tammisto T. Effect of the trendelenburg tilt and other procedures on the position of endotracheal tubes. Lancet 1969;1(7600):850-3.

[38] Kelly JD, McCoy D, Rosenbaum SH, et al. Haemodynamic changes induced by hyperbaric bupivacaine during lateral decubitus or supine spinal anaesthesia. Eur J Anaesthesiol 2005;22(9):717-22.

[39] Thomas PJ, Paratz JD. Is there evidence to support the use of lateral positioning in intensive care? A systematic review. Anaesth Intensive Care 2007;35(2):239-55. 